\title{
New urban developments: flood control and LID - a sustainable approach for urban drainage systems
}

\author{
M. G. Miguez, J. M. Bahiense, O. M. Rezende \& A. P. Veról \\ Universidade Federal do Rio de Janeiro, Brazil
}

\begin{abstract}
The relation between the water and the city is very close. Water is essential for city development, although urban floods may heavily affect city life. The urban layout defines new patterns for natural drainage system and changes the hydrological cycle, increasing peak discharges. Since the beginning of the Industrial Age, urban drainage systems were designed to face sanitation problems and adequate the system to the exceeding runoff. Traditional flood control projects tended to focus on improving discharge capacity. The concept of sustainability in urban drainage, however, implies that urban floods may not be simply transferred and the drainage systems have to be planned jointly with urban development. Storage and infiltration measures distributed over the basin and integrated with urban landscape should be introduced to reduce flood peaks. Following this line of action, the concept of low impact development (LID) may be a reference for urban drainage projects. This concept tends to produce built environments with minor hydrological changes, trying to preserve or recover natural flow conditions prior to urbanisation. This paper discusses urban flood problems, starting from a conceptual perspective and compares different possibilities for developing a new urban site. This way, a non-urbanised area in Rio de Janeiro City, Brazil, was chosen as case study to simulate different approaches for an urban expansion. A sustainable approach, considering LID concepts, allowed an economic and effective micro-drainage system design, at the allotment level, while it has improved the macro-drainage system response, in the basin scale.

Keywords: urban site development, sustainable urban drainage, low impact development, mathematical modelling, MODCEL.
\end{abstract}




\section{Introduction}

The standards required to meet a sustainable city compose a complex and multidisciplinary issue. The city is made up of several interconnected nets and services that work together and interact with each other. Housing, urban infrastructure systems, mobility and accessibility, recreation and open spaces, among others, are all key elements to be integrated when considering urban planning. The present study will particularly address urban drainage, which is an important system that affects several aspects of city life. Urban floods, resulting from drainage system failure, affect and disrupt city infrastructure on a broad scale. Urban flooding process degrades the built environment and produces great losses of several types. Sometimes, lives are lost. Most frequently, however, dwellings are damaged, people lose their shelter, the transportation system is disrupted, the local economy is affected, sanitation conditions worsen, the population's health is put at risk, and natural environmental conditions are deteriorated.

The relation between urban development and urban drainage is very close and they affect each other like a carousel. The urban layout dictates new patterns for the natural drainage system and changes the water cycle parcels: peak discharges increase and flow faster. Vegetation removal and the sealing of large surface areas produce more runoff and the designed streets define new superficial flow paths. In this context, urban development increases flood levels, which, by their side, affect the urban areas that were responsible for changing the drainage patterns.

It is possible to say that floods in urban areas consist of one of the most common, serious and costly problems that cities have to deal with nowadays. Looking at the records of economic losses due to floods and other climaterelated disasters over the past decades, there is clearly a trend of increasing losses associated with these phenomena. According to studies undertaken by the Geosciences Division of Munich Re America, the economic losses caused by natural disasters in the United States, in the middle of the twentieth century, were about $\$ 30$ billion, while between 1990 and 1999 these losses grew to something around $\$ 210$ billion (Grossi and Kunreuther [1]).

Urban drainage systems have been designed to face urban flood problems and equate the expected consequences, not really looking to mitigate the causes. Traditional flood control projects, mainly referring to canalisation practices, tend to focus on the resultant increased flow conditions and work to provide a greater discharge capacity to the drainage system. Urban drainage conception, however, has been changing a lot over the last few years, trying to pose a more sustainable approach. Recent practices involve the concept of low impact development LID (Coffman etal. [2]), which tends to produce built environments with minor hydrological changes, trying to recover natural conditions, working with infiltration and retention measures, and extending flow paths to increase the flow concentration time.

This paper intends to discuss urban flood problems, starting from a conceptual perspective and to compare different possibilities for developing a 
new urban site, looking to the allotment scale and its interaction with the catchment. In this context, a non-urbanised area in the neighbourhood of Guaratiba, in Rio de Janeiro City, Brazil, was chosen as a pilot case study for testing different approaches related to urban expansion. Two different approaches will be compared: a traditional urban drainage project and an LID project conception for the drainage system. The studied area drains directly to Cabuçu River and the effects of the different approaches will be assessed also in the river basin scale. Then, two different design rainfall events will be considered, one taken as the critical event for local scale design, and the other considered as the river basin critical event. It is expected that a more sustainable approach, considering the LID concepts, will lead to an economic and effective micro-drainage system design, at the allotment level, while also improving the macro-drainage system response, in the basin scale, with positive results for the city as a whole.

\section{City development and urban drainage}

The rate of urbanisation at the beginning of the Industrial Revolution was only about $2 \%$. In 2000, the urbanisation rate was about $51 \%$ worldwide. The industrial city grew fast and with very little guidance, in the first moments of the Industrial Age (Benevolo [3]). Sanitation became one of the greatest problems of that time and inadequate waste disposal led to several sort of diseases and deterioration of public health. Departing from sanitation needs, the hygienist concept arose in the drainage design, with the aim of conveying as quickly as possible the stormwater and sewerage away from the contact with people settled in the urban areas. Canalisation and storm drains became a frequent solution in drainage systems. From the end of the nineteenth century and until the 1970s, urban drainage focused on increasing the conveyance and the need to improve the flow conditions to face the increased flood levels generated by city growth.

Since 1970, however, the traditional paradigms began to fall (Andoh and Iwugo [4]). The traditional approach for urban drainage showed to be not sustainable, once canalisation measures tended to transfer flood problems to downstream areas. Design concepts started to change, in order to promote the urban runoff control near to its sources. The urban drainage system projects evolved concerning the following aspects:

- storage and infiltration techniques were adopted to control flow generation;

- distributed source controls were introduced to recover natural flow patterns and to promote a low impact development over the water cycle;

- quantity and quality concerns started to be considered in an integrated manner;

- the sustainable drainage concept was formalised - urban flood problems should not be transferred, neither to other places, nor to a future time;

- drainage solutions started to be considered in an integrated way with socioenvironmental aspects;

- rainwater harvesting became to be seen as a usable resource, increasing the urban water availability. 
In recent years, the design of flood control projects for urban drainage has been seeking to integrate actions to build a balanced, harmonious and sustainable urban environment. The basin, considered in this systemic approach, is then taken as the basic planning and design unit.

\section{Sustainable urban drainage}

The concept of sustainability in urban drainage implies to consider an integrated approach, where urban floods may not be transferred and the drainage systems have to be planned in close alignment with urban growth. Distributed measures over the basin should be introduced in order to reduce or delay flood peaks, to allow the recharging of groundwater and to seek the restoration of the approximate natural flow conditions prior to urbanisation. In general, different types of storage and infiltration measures are proposed as the most frequent actions to fulfil this aim. Some examples of these measures include detention ponds, retention basins, infiltration trenches, and pervious pavements, among others. These measures may also be combined and integrated with urban landscape, assuming the character of multifunctional landscapes.

Figure 1 schematically shows the behaviour of a natural and an urbanised catchment, considering the traditional approach for the urban drainage system, and an urbanised watershed where the sustainable development approach is considered.

Souza et al. [5] discussed and proposed a methodology to apply on sustainable urban land subdivision in blocks and lots. This approach is similar to the concepts proposed by Coffman et al. [2]. Briefly resumed, this methodology is based on the following steps:

- clear identification of the applied regulation in terms of urban zoning, land use and others;

- comparison between pre and post development scenarios, assessing hydrologic changes and quantifying the level of control desired in the planning and design processes;

- definition of natural areas to be protected and the desired conditions that will guide future developments;

- reduction of land surface modifications;

- utilisation of local natural "footprints", which means to privilege the use of natural flow paths, instead of proposing artificial drains, minimising vegetation removal and disconnecting impervious areas from the drainage system, favouring all infiltration opportunities;

- minimisation of impervious rates, using green roofs, porous pavements, rain gardens, and narrow streets;

- focus on natural hydrological aspects as a design element, controlling the excess of discharge generation and increasing drainage paths;

- definition of optimal sites for parks and storage opportunities, as well as integrating this hydrological aspects with urban landscapes;

- development of integrated management practices to make low impact development effective. 


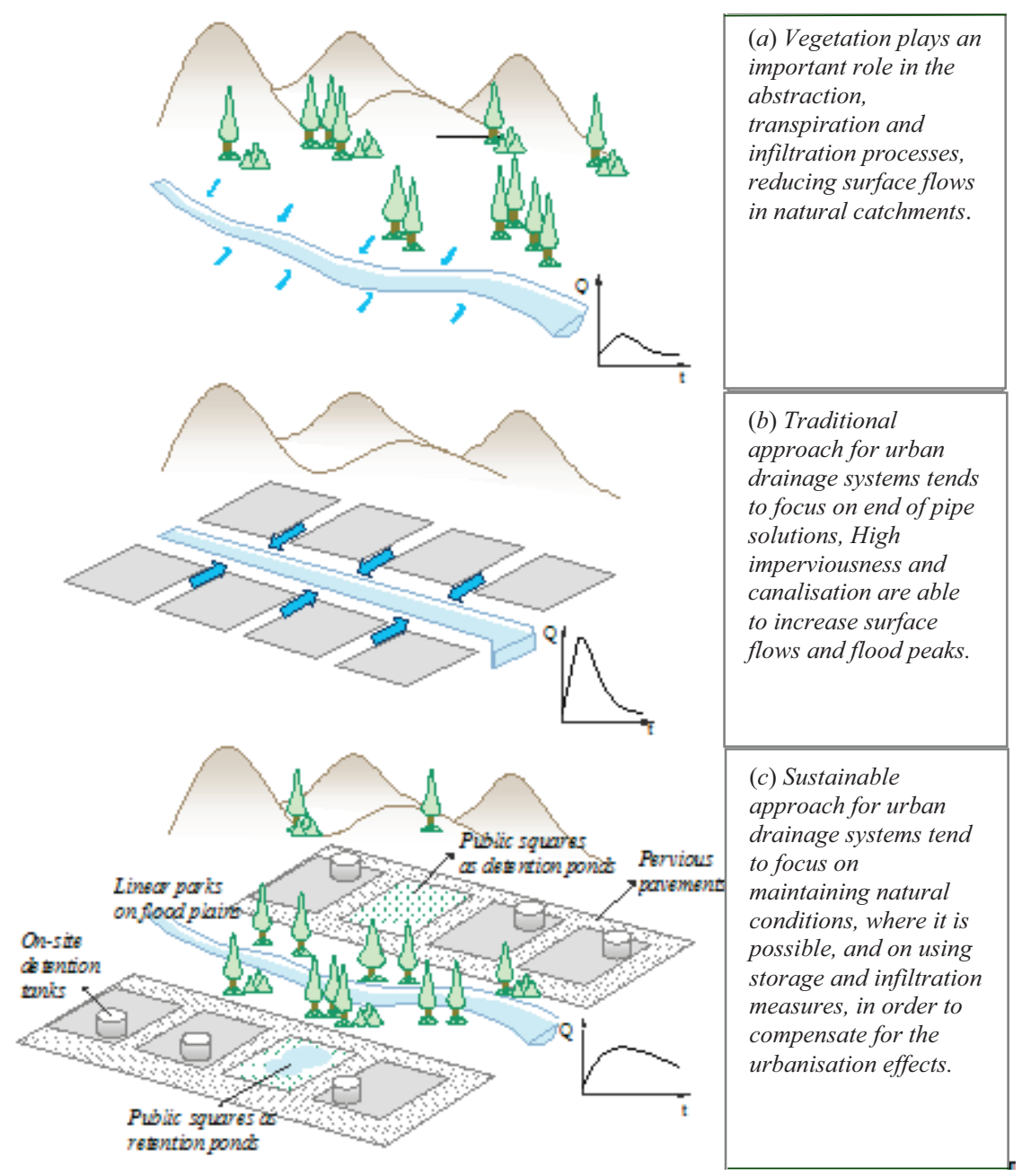

Figure 1: (a) Urbanisation process, (b) traditional drainage design and an alternative sustainable approach.

Andoh and Declerck [6] made some interesting considerations regarding flood control design choices. These authors stated that distributed or on-source control measures present minor costs when compared to end-of-pipe solutions. This cost reduction varies from $25 \%$ to $80 \%$ and is more significant in plain watersheds. Besides, distributed control of flows generated by the urbanisation process shows an attractive possibility of combining flood control measures with interventions that add value to the urban landscape. Another interesting point is that on-source control measures demand the use of a large number of small structures, which can be built with minor undesirable effects, minor costs and minor possibilities of system failures. 


\section{Case study - a new allotment at Guaratiba neighbourhood in Rio de Janeiro City}

The present work will develop a discussion on different possibilities of designing a drainage system for an urban development in a new site.

Guaratiba is a neighbourhood in the west zone of Rio de Janeiro City, in an expanding urban region. The chosen site for the new development proposed here is situated on Cabuçu River basin and occupies a riverine area. Figure 2 shows the plain view of this area, while figure 3 shows the correspondent aerial view and the proposed allotment design.

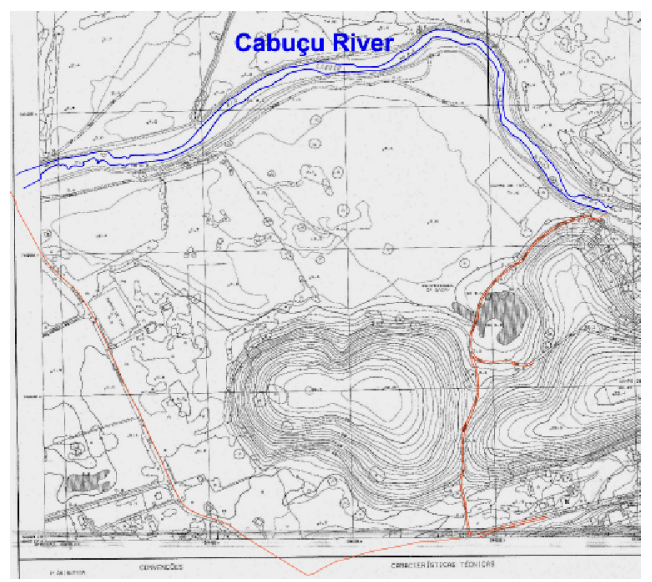

Figure 2: $\quad$ Plain view of the case study area.
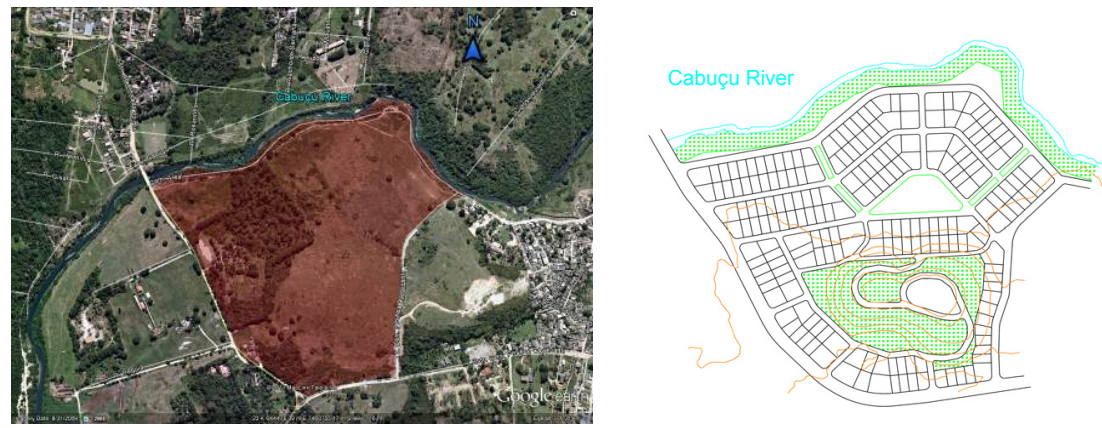

Figure 3: (a) Aerial view of the case study area. (b) Allotment project proposed for the urban site development on the case study area.

Departing from this base, two different design scenarios are proposed for assessing drainage possible solutions: 
- Scenario 1: defines a traditional design for the drainage system, conveying discharges in pipes and channels, looking for fast eliminating the generated runoff and avoiding local site inundation.

- Scenario 2: considers the low impact development approach, working with drainage disconnections, storage detention and infiltration on lots, square detention ponds in public areas, and flow paths increasing.

The first scenario will be constructed for the local rainfall event, in a traditional design process, associated with a return period of 10 years, as recommended for micro-drainage projects, and with a duration equivalent to the concentration time of the local catchment, which is the critical event for this situation. This scenario will also be simulated with the aid of a mathematical model, for a second rainfall event. The critical situation for Cabuçu River basin scale will be considered, using its concentration time to define the rainfall duration. In this case, a return period of 25 years will be used, as proposed by Rio de Janeiro Municipality for macro-drainage design. With these calculations, and considering the present situation as the basic reference for comparisons, it will be possible to evaluate the increasing in flood peaks promoted by the new urban development, both in local and basin scales.

The second scenario will be designed to minimise the allotment impact. Mainly, three actions will be considered:

- All lots will have their garden area lowered $10 \mathrm{~cm}$, in order to receive roof tops and other impervious areas contribution (figure 4). In practice, for simulation purposes, the garden area will be assumed as $30 \%$ of the total area. Only the waters exceeding the storage volume will be conducted to the drainage net. The stored volume will be infiltrated along time. In this case, rain gardens must be favoured and combined with the strategy of lowering ground levels to produce a storage capacity.

- The central green alleys that appear in two downstream streets will be used to increase flow paths and as a temporary storage (figure 5). These alleys, with $10 \mathrm{~m}$ wide will receive a sinuous channel, approximately $50 \%$ longer than the original pipes.

- The central square will be used as a temporary detention pond, in a multifunctional landscape configuration.

Considering that this second solution depends on volume values, only the basin critical rainfall event will be considered, once it corresponds to the event of greater duration and greater recurrence. Therefore, this is the situation associated with the higher volumes involved. The total allotment area approximately covers $350,000 \mathrm{~m}^{2}$, the concentration time estimated for this area was 38 minutes, while the concentration time found for Cabuçu River basin at the allotment site was 228 minutes. A total rainfall of $47.2 \mathrm{~mm}$ was calculated for 10 years of return period, in 38 minutes. Considering the return period of 25 years and duration of 228 minutes, the total rainfall was $87.8 \mathrm{~mm}$. 


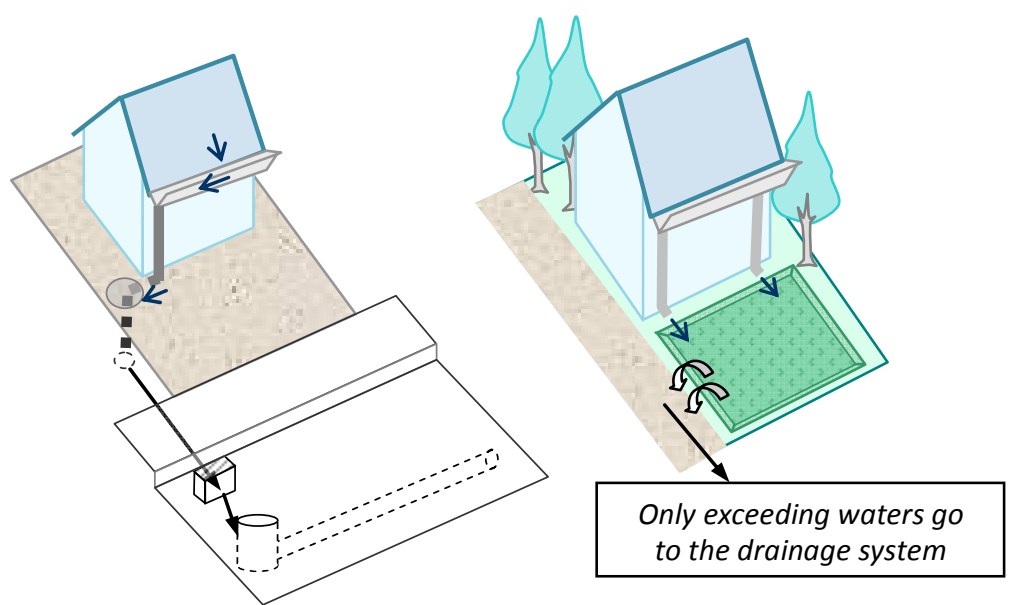

Figure 4: Proposition for lot occupation considering a storage capacity in the garden area.

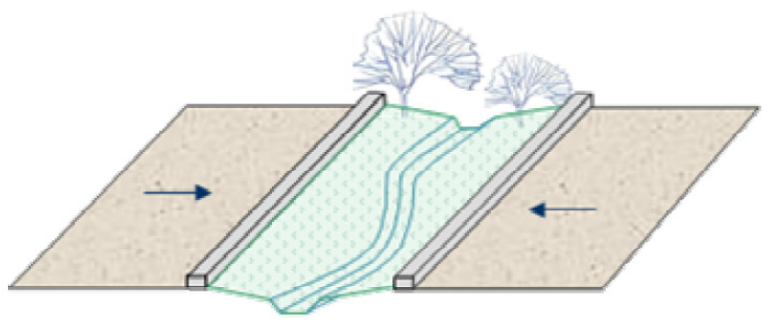

Figure 5: Proposition of a sinuous open channel in a green alley as an alternative to the pipes of the main streets.

\section{Mathematical model aid}

A mathematical model conceived for urban flood simulation was used to represent the two development scenarios proposed in the previous item. MODCEL (Mascarenhas et al. [7]) was developed in the Federal University of Rio de Janeiro and encompasses hydrological and hydrodynamic features. This is a computational program that is able to simulate watersheds subject to flooding events, integrating surface flows with the drainage system. This model assumes that the basin can be represented by interconnected compartments that represent urban landscape, channel and pipes in an integrated way. These compartments are called flow cells, and the cells cover the entire modelled surface, composing a complex flow net linked by one-dimensional hydraulic equations, defined according to the topography and the urban patterns of the region. Saint-Venant dynamic equation is used to represent channel flows and mass balance is applied to all cells. 


\section{Results and discussion}

\subsection{Scenario 1}

The traditional drainage system project for the allotment area is shown in Figure 6. It was designed to quickly drain the catchment through pipes, discharging stormwaters in four different points of Cabuçu River.

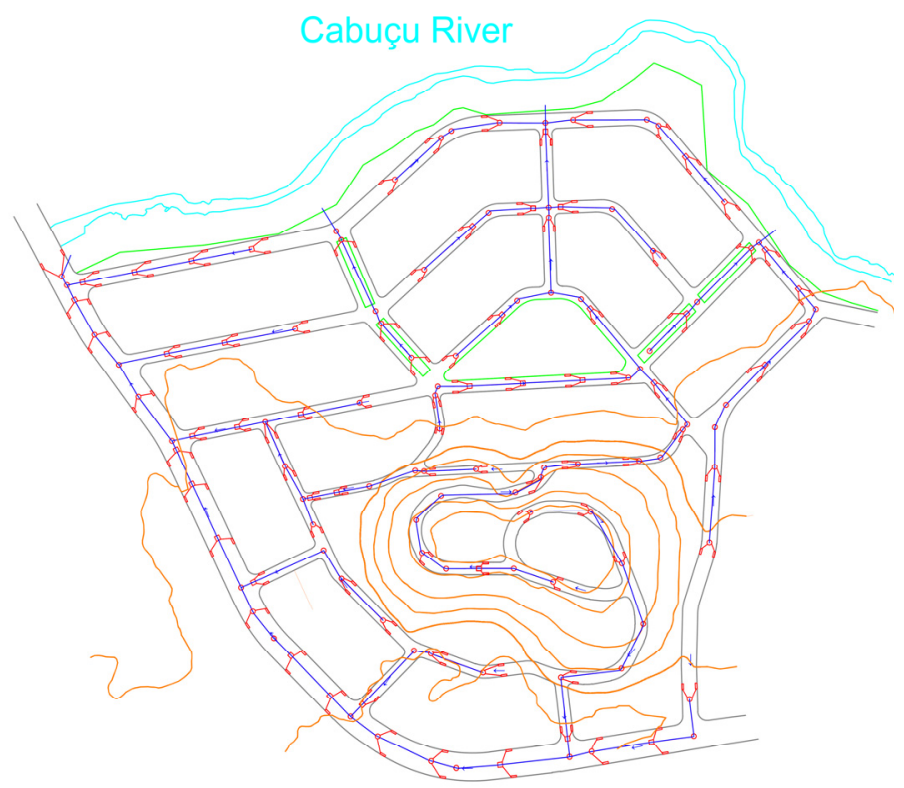

Figure 6: Traditional drainage system designed for the new allotment area.

Pre-urbanised catchment was simulated considering the aid of a hydrological model, both for the local scale and Cabuçu River basin scale. Analysing hydrographs shown in Figure 7, it is possible to notice a reduction in the peak time, after the new urban development. Considering the local rainfall event, with a 10 years rainfall event, the natural area outflow has a peak time of 45 minutes, while the urbanised area has a peak time of 38 minutes. Other effect of the traditional allotment design is the rise in magnitude of peak flow, which increased from $1.45 \mathrm{~m}^{3} / \mathrm{s}$, in pre-urbanised scenario, to $4.20 \mathrm{~m}^{3} / \mathrm{s}$, in urbanised scenario. For the basin scale, the modified patterns are similar.

\subsection{Scenario 2}

The main changes on the traditional drainage design are detached in figure 8, showing the location of the square reservoir, the alleys and the use of residential garden areas as temporary storage and infiltration measures. 


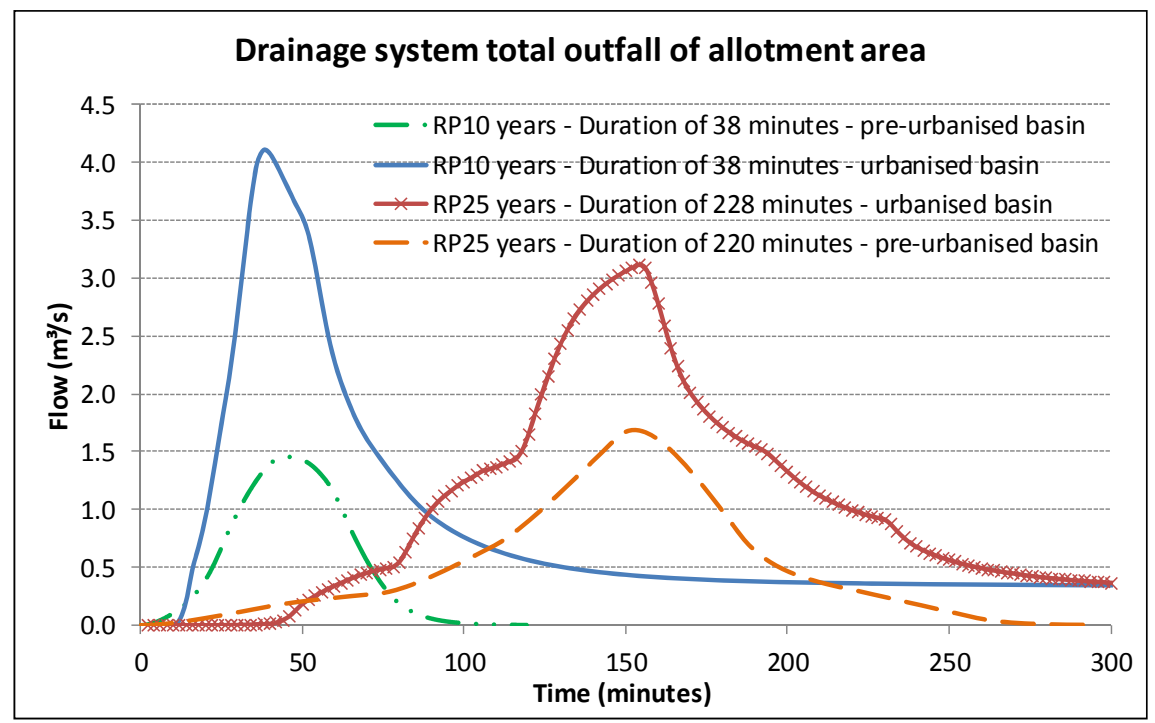

Figure 7: $\quad$ Total outfall of allotment drainage system and pre-urbanised area-Scenario 1.

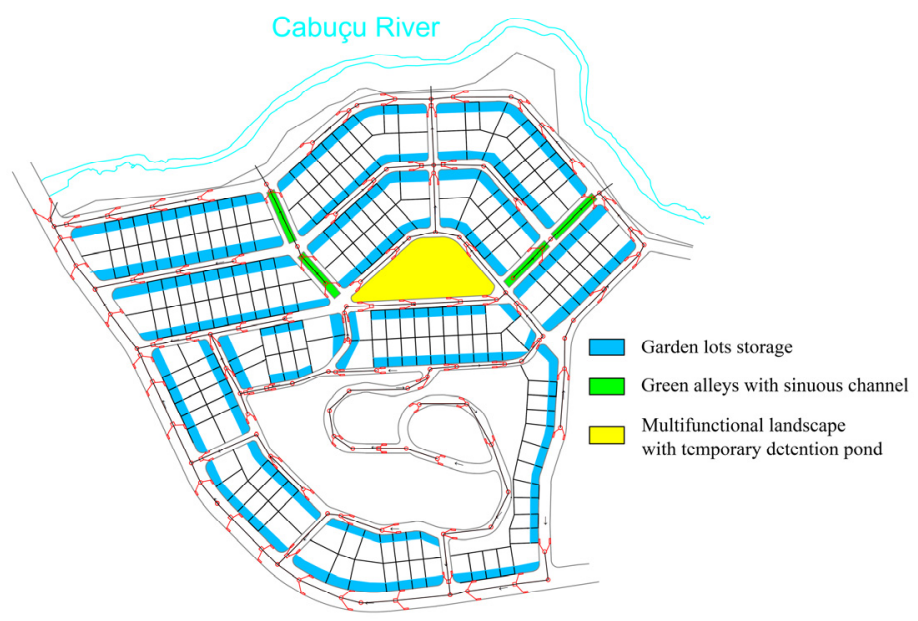

Figure 8: $\quad$ Location of the proposed LID interventions - Scenario 2.

The results obtained at the outfall of the basin in the new developing scenario are shown in Figure 9, considering the basin scale, where the rainfall volumes are greater (due to the longer critical rainfall event). Reduction in peak discharges, controlling runoff generation, is noticed, when compared with the traditional approach and even with the modelled natural flow patterns. 


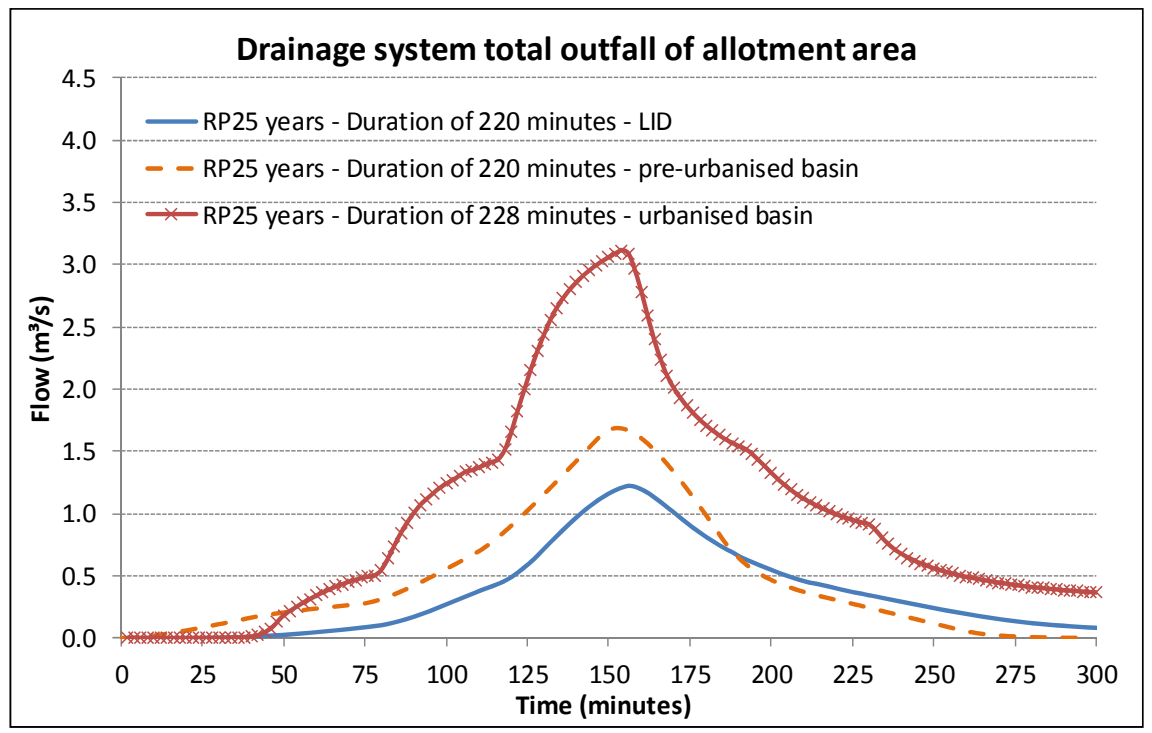

Figure 9: Total outfall of allotment drainage system and pre-urbanised area Scenario 2

It is interesting to see that it is possible to recover pre-urbanisation patterns, even obtaining better results. This may be a desirable fact where catchments are already densely occupied and new developments may be able to compensate for past errors, in order to minimise present flooding conditions. In particular, it is important to stress that the most effective measure proposed in this new allotment configuration was the on-site storage and infiltration in the garden lots. The square detention pond proposed showed also greater efficiency by reducing by $85 \%$ the discharges deviated to its interior.

\section{Concluding remarks}

The obtained results show how important is the urbanisation process and its effects on the drainage system behaviour. Traditional urban development, without accounting for urban water cycle changes may be one of the most important causes of urban floods worsening. The adoption of a low impact development strategy in the proposed allotment design showed to be able to control flow generation, preserving and even upgrading the original storage and infiltration volumes, which can be an important achievement, when dealing with basins already suffering from flood problems and where urban development is mostly consolidated in traditional terms. Besides, it was noticed a reduction in pipes and channel cross section needs, resulting in the possibility of economic gains also in the building process. At last, but not less important, the conception proposed may also allow an improvement in landscaping, with green alleys, rain gardens and the use of multifunctional landscapes. This last option usually helps 
to optimise public investments, due to the combination of different functions in the same intervention. In this case, the public square will be used for recreational purposes, but also as a temporary reservoir during the rainfall.

It is important to integrate and conjugate aspects of civil and hydraulic engineering with urban and landscape design, in order to find a real sustainable path for growing cities.

\section{Acknowledgement}

The authors acknowledge CNPq for the scholarships and FINEP for the support.

\section{References}

[1] Grossi, P., Kunreuther, H. Catastrophe Modeling: A New Approach to Managing Risk. Springer. New York, USA. 2005.

[2] Coffman, L.S., Cheng, M., Weinstein, N., Clar, M. Low-Impact Development Hydrologic Analysis and Design. In: Loucks, E.D. (editor), Water Resources and The Urban Environment - Proceedings of the 25th Annual Conference on Water Resources Planning and Management, Chicago-Illinois. American Society of Civil Engineering, New York, p. 1-8, 1998.

[3] Benevolo, L. Storia della città. Vol. 4: La città contemporânea, p. 332, $2^{\mathrm{a}}$. ed. Gius. Laterza \& Figli, Roma-Bari, Italia, 2006.

[4] Andoh, R. Y. G.; Iwugo, K. O. Sustainable Urban Drainage Systems: A UK Perspective. $9^{\text {th }}$ ICUD Conference, Portland, Oregon, USA, 2002.

[5] Souza, F.C., Tucci, C.E.M., Pompêo, C.A., Diretrizes para o Estabelecimento de Loteamentos Urbanos Sustentáveis. VI Encontro Nacional de Águas Urbanas. Belo Horizonte, Brazil, 2005.

[6] Andoh, R.Y.G., Declerck, C., Source control and distributed storage - a cost effective approach to urban drainage for the new millennium? Proceedings of the 8th International Conference on Urban Storm Drainage, Sydney, Australia. 30 August - 3 September, pp. 1997-2005, 1999.

[7] Mascarenhas, F.C.B.; Toda, K.; Miguez, M.G.; Inoue, K. Flood Risk Simulation. WIT PRESS, Southampton and Boston, 2005. 